\title{
A case report of rhino-facial mucormycosis in a non-diabetic patient with COVID-19: a systematic review of literature and current update
}

\author{
Faezeh Mohammadi ${ }^{*}$ (D), Milad Badri ${ }^{2,5}$ (D) Shapoor Safari ${ }^{3}$ and Nima Hemmat ${ }^{4}$
}

\begin{abstract}
Background: COVID-19 disease may be associated with a wide range of bacterial and fungal infections. We report a patient with COVID-19 infection who developed rhino-facial mucormycosis during treatment with corticosteroids.

Case presentation: A 59-year-old non-diabetic male patient was admitted with a diagnosis of COVID-19 based on positive RT-PCR and CT of the lungs. Due to sever lung involvement, he was treated with methylprednisolone. The patient was re-admitted to hospital, due to nasal obstruction and left side facial and orbital swelling, several days after discharge. In sinus endoscopic surgery, debridement was performed and the specimens were sent to pathology and mycology laboratories. A nasal biopsy showed wide hyphae without septa. The sequenced PCR product revealed Rhizopus oryzae. Despite all medical and surgical treatment, the patient died. In addition, the characteristics of patients with COVID-19-associated mucormycosis were reviewed in 44 available literatures. In most studies, diabetes mellitus was the most common predisposing factor for mucormycosis.
\end{abstract}

Conclusion: Our report highlights the need for assessing the presence of mucormycosis in patients with COVID-19 and also it shows that physicians should consider the potential for secondary invasive fungal infections in COVID-19 cases.

Keywords: COVID-19, Mucormycosis, Rhizopus oryzae

\section{Background}

COVID-19 is a viral disease of the respiratory tract that continues to be a major health issue worldwide. The disease is associated with common symptoms such as fever, dry cough, fatigue, and shortness of breath and sometimes in severe cases, leads to acute respiratory distress syndrome (ARDS) [1]. On the other hand, the use of corticosteroids to modulating lung injury and reduce

\footnotetext{
*Correspondence: Faezehmohamadi119@yahoo.com

${ }^{1}$ Department of Medical Parasitology and Mycology, School of Medicine, Qazvin University of Medical Sciences, Shahid Bahonar Blvd, PO Box: 34199-15315, Qazvin, Iran

Full list of author information is available at the end of the article
}

mortality in COVID-19 patients may be exposes the patient to opportunistic bacterial and fungal infections [2].

Invasive pulmonary aspergillosis is one of the fungal diseases that complicates COVID-19 manifestations [3]. Moreover, mucormycosis as an opportunistic fungal infection can progress rapidly in immunocompromised patients. The most common clinical form of this fungal infection is rhino-cerebral mucormycosis [4]. We reported a case of rhino facial mucormycosis in a 59-year-old non-diabetic male patient with COVID-19 following corticosteroid treatment, which eventually resulted in death. 


\section{Case presentation}

A 59-year-old non-diabetic male patient without any underlying disease with clinical symptoms of cough, shortness of breath, and oxygen saturation of $76 \%$ was admitted to Razi Hospital, Qazvin, Iran. His vital signs included body temperature of $37.6{ }^{\circ} \mathrm{C}$, blood pressure value of 140/85 (mm $\mathrm{Hg})$ and oxygen saturation of $76 \%$. Positive results of chest X-ray test (CXR), computed tomography $(\mathrm{CT})$ scan of lungs and positive reverse transcriptase polymerase chain reaction (RT-PCR) showed a definite diagnosis of COVID-19 (Fig. 1).

He was treated with remdesivir injection at a dose of $250 \mathrm{mg}$ stat and then $100 \mathrm{mg}$ daily. The patient was under supportive care for six days, and thereafter methylprednisolone was administered at a dose of $250 \mathrm{mg}$ stat and then $125 \mathrm{mg}$ for 3 days. After 10 days, the patient was discharged while he was relatively in good general condition. Four days after his discharge, the patient was readmitted to hospital because of nasal obstruction and left side facial and orbital swelling. Table 1 shows the laboratory findings of the patient during both COVID-19 and mucormycosis. Subsequently, the patient visited by an infectious disease specialist and due to the involvement of the left ethmoid, sphenoid, and maxillary sinuses, a CT scan was performed (Fig. 2). In sinus endoscopic surgery, by Rhinologist, severe involvement and necrosis of the left side lateral nasal wall, floor, and septum as well as left ethmoid and sphenoid sinuses were observed and also destruction of the left orbital floor and medial wall were observed. Since clinical results confirmed the possibility of mucormycosis in the patient, treatment with IV liposomal amphotericin B (3 $\mathrm{mg} / \mathrm{kg} /$ day, according to local guidelines [5]) was started. In addition, the patient underwent daily paranasal sinuses debridement and

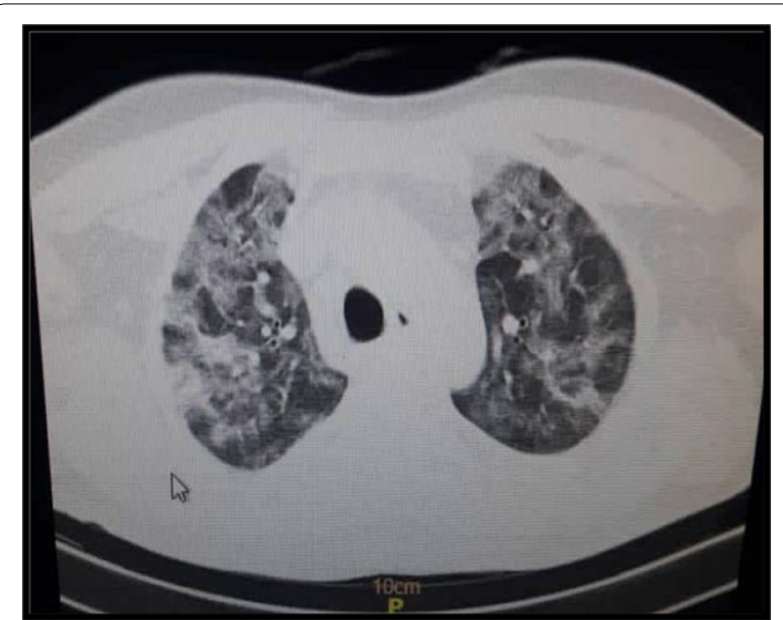

Fig. 1 Computed tomography (CT) scan of the chest of a patient with COVID-19 shows multiple patchy ground-glass opacities
Table 1 The measured hematological biomarkers in blood of the patient

\begin{tabular}{lll}
\hline Categorization of hematological factor & $\begin{array}{l}\text { At the time of admission } \\
\text { to }\end{array}$ \\
\cline { 2 - 3 } & Covid-19 & Mucormycosis \\
\hline White Blood Cell (WBC) Count, $\mu \mathrm{L}$ & 10,400 & 18,100 \\
Red Blood Cell Count (RBC),million/ $\mu \mathrm{L}$ & 5.1 & 4.5 \\
Hemoglobin (Hb), mg/dL & 15.8 & 14.1 \\
Platelets, $\mu \mathrm{L}$ & 136,000 & 137,000 \\
Neutrophil count, \% & 88.1 & 94.7 \\
Lymphocyte count, \% & 7.7 & 1.8 \\
C-Reactive Protein (CRP) & 48.1 & 55.8 \\
Blood urea nitrogen (BUN), mg/dL & 25.2 & 28.4 \\
Serum creatinine, mg/dL & 1.59 & 1.24 \\
Sodium Blood, mEq/L & 146 & 144 \\
Potassium Blood,mEq/L & 4 & 4.6 \\
\hline
\end{tabular}

irrigation with diluted amphotericin B. Biopsy of sinonasal area was made and the specimens were sent to both pathology and mycology laboratories. Examination of the results with haematoxylin and eosin (H\&E) staining and direct experiment with $10 \%$ potassium hydroxide $(\mathrm{KOH})$ showed irregular hyphae, wide and aseptate (Fig. 3).

In addition, the sample was inoculated on PDA (SigmaAldrich,UK) and was incubated for $4-5$ days at $37^{\circ} \mathrm{C}$. After colony growth, non- septate hyphae, rhizoids and spore-filled sporangiophores were observed in slides prepared with LCB (Fig. 3). The antifungal susceptibility

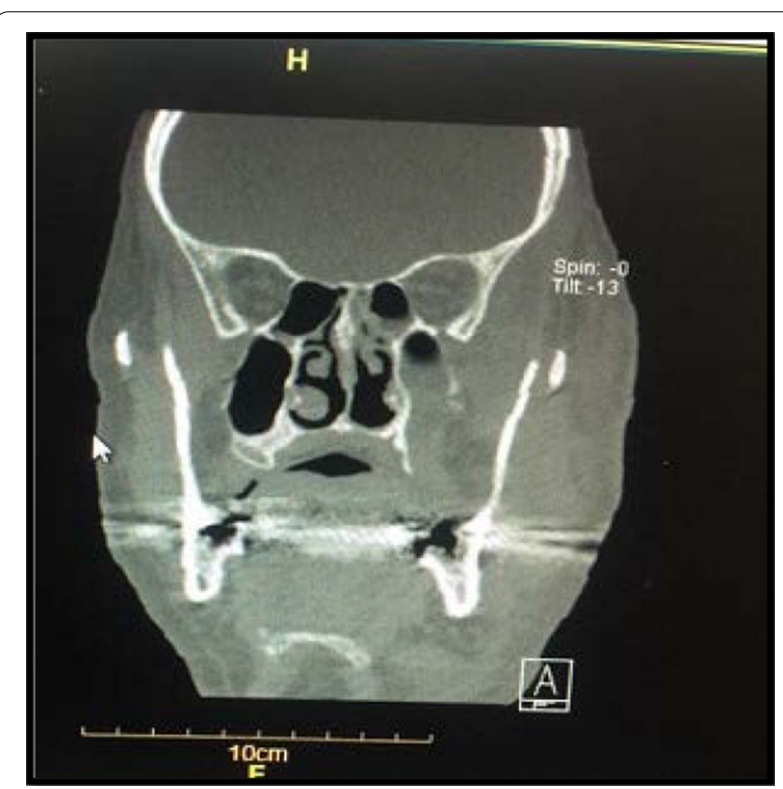

Fig. 2 CT scan shows involvement of the left ethmoid, sphenoid, maxillary and paranasal sinuses in a patient with mucormycosis 


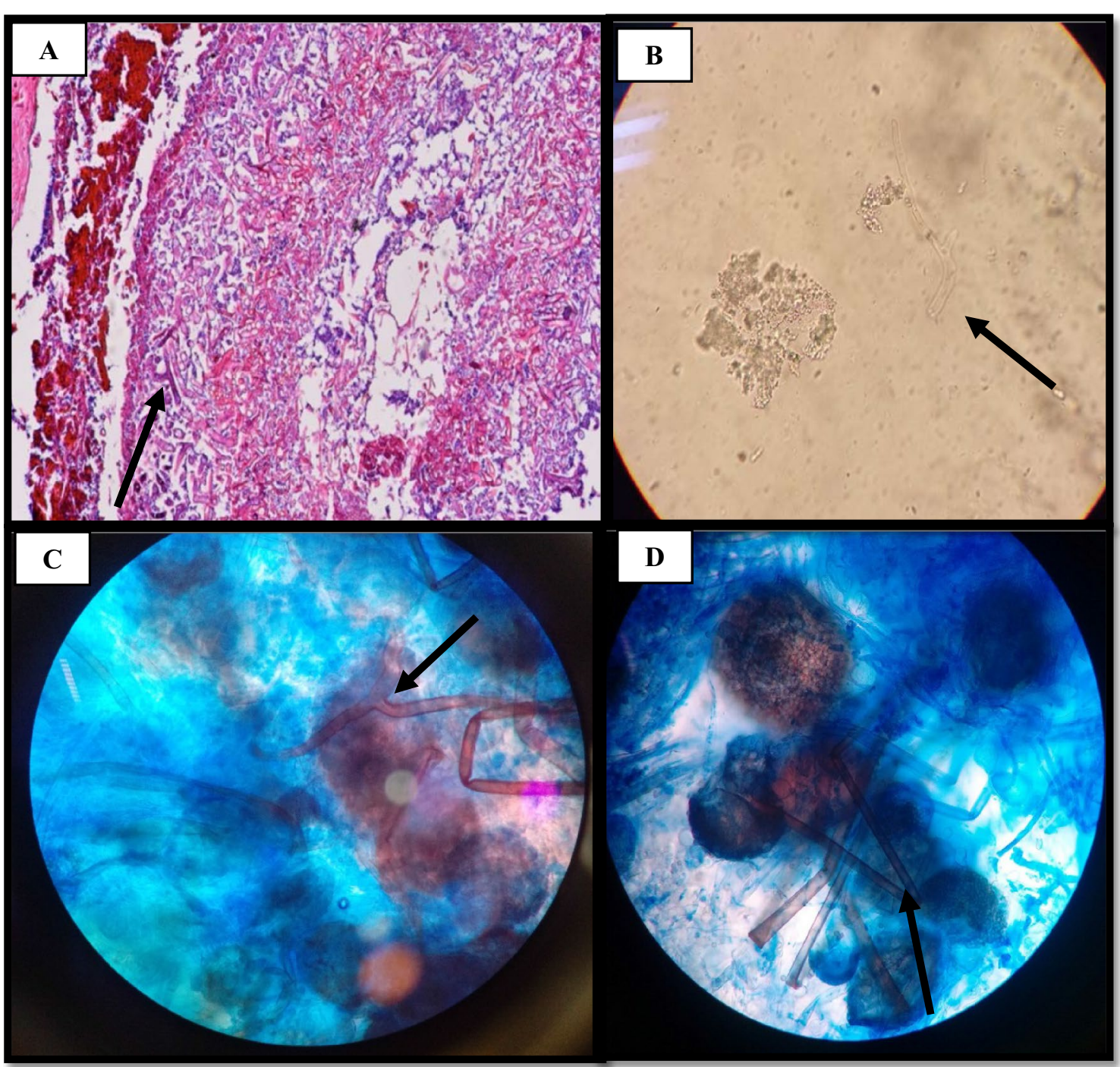

Fig. 3 a Presence of irregular and non-septate hyphae in H\&E staining of pathology. b Observation of broad aseptate hyphae in surgical debridement in direct examination (10\% KOH). $\mathbf{c}$ and $\mathbf{d}$ Lactophenol cotton blue (LCB) mount showed nonseptate hyphae, rhizoids and spore-filled sporangiophores

testing was performed in 96-well plates by following the M38-A2 guidelines of the CLSI for in vitro testing. MIC values against $A M B$, ITC and VRC were $0.5 \mathrm{mg} / \mathrm{mL}$, $16 \mathrm{mg} / \mathrm{mL}$ and $32 \mathrm{mg} / \mathrm{mL}$, respectively. In the next step, DNA extraction was carried out using the glass beads and phenol:chloroform:isoamyl alcohol (25:24:1) method, previously described [6]. The fungal isolate was identified by molecular analysis of ITS1-5.8S-ITS2 region using the primers for ITS1 ( $5^{\prime}$-TCCGTAGGTGAACCTGCGG-3') and ITS4 $\left(5^{\prime}\right.$-TCCTCCGCTTATTGATATGC- $\left.3^{\prime}\right)$. The sequenced PCR product showed $100 \%$ sequence identity with $R$. oryzae and it was registered in the GenBank database under the assigned accession number MW317184.
Sequence was aligned with using the ClustalW algorithm as implemented in Bioedit version 7 (http://www.mbio. ncsu.edu/BioEdit/bioedit.html). The molecular diversity of the sample was estimated by phylogenetic analysis via MEGA7 software. In order to compare the sequences with available DNA sequences in GenBank, the nucleotide BLAST with the BLASTn algorithm was applied through CLUSTAL omega (https://www.ebi.ac.uk/Tools/ $\mathrm{msa} / \mathrm{clustalo} /$ ). The protocols were conducted based on the ML method using the Tamura-Nei model. The number of bootstrap replications was considered to be 1000 (Fig. 4). Because of the progression of the disease and the involvement of the cheeks and orbit, necrotic tissues 


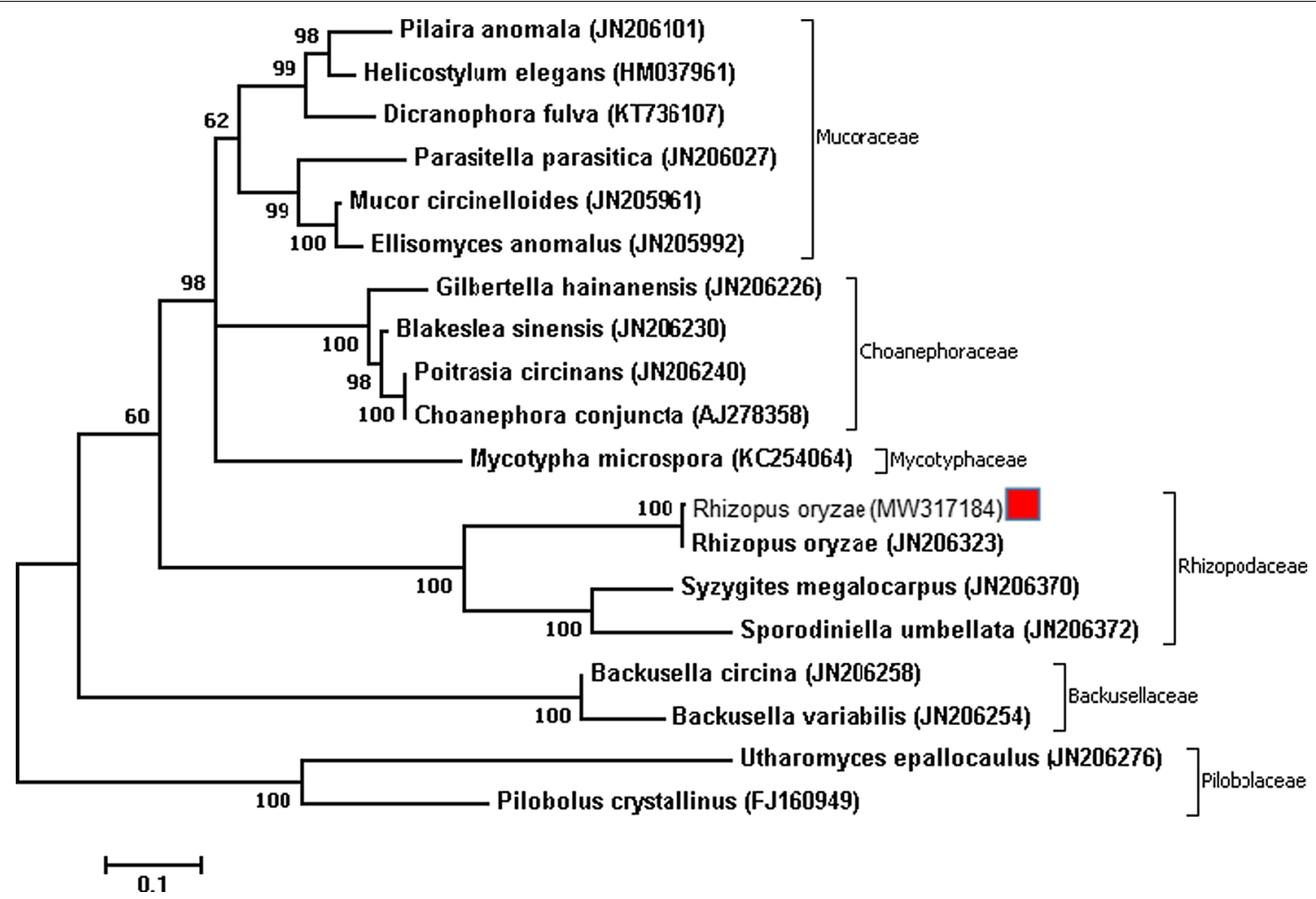

Fig. 4 The phylogenetic tree of isolates of Rhizopus oryzae. Based on ITS sequence from a patient with mucormycosis and GenBank sequences of some related species were estimated in MEGA7 using the ML analyses based on 1,000 bootstrap replications

were removed. Despite all measures, the patient unfortunately expired on the seventh day of his admission due to loss of consciousness and involvement of central nervous system.

\section{Discussion and conclusions}

COVID-19 disease has a rapid and widespread distribution with mild to severe symptoms. Supportive care, corticosteroids and remedial drugs are good treatment options in COVID-19. On the other hand, due to the use of steroids, these patients may be susceptible to invasive mould infections. Furthermore, diabetes mellitus complicates the management of Covid-19 infection.

Mucormycosis is an acute fungal infection caused by the members of mucoraceae family. Mucormycosis in uncontrolled diabetic patients and immunocompromised is an opportunistic and fatal fungal disease [7]. The most common clinical manifestation of mucormycosis in immunocompromised patients is the rhino-orbitocerebral form [8]. Infection begins in the nasal cavities and paranasal sinuses. The symptoms of mucormycosis include one-sided facial swelling, headache, fever, inflammation, eyelid drooping and black lesions on nasal that the disease spreads rapidly [9]. Infarction and necrosis of host tissues occur due to invasion of non-septate hyphae [10]. Methods for diagnosing mycromycosis include histopathology, direct testing, and culture of clinical specimens [11]. The first line of management of mucormycosis is recommended injection of liposomal amphotericin B. In case of intolerance of the treatment regimen or general weakness of the patient, azole compounds such as Posaconazole and Isavuconazole can be used [5].

The database search using the terms "COVID" OR "SARS-CoV2" OR "Coronavirus" AND "Mucor" OR "Zygomycosis" revealed a total of 44 articles. The characteristics of patients with COVID-19-associated mucormycosis were shown in Table 2.

Review of literature published till June 2021 shows that the most cases are related to mucormycosis in COVID19 patients was in India with 110 cases [12-25], followed by Iran (20 cases) [26-30], Turkey (12 cases) [31, 32], Egypt (11 cases) [33, 34], the United States and (10 cases) [35-43], the Netherlands (4 cases) [44], UK and Spain (2 cases) [45-47]. Furthermore, a case of mucormycosis in COVID-19 patients has been published from Brazil [48], Australia [49], France [50], Mexico [51], Italy [52] and Iraq [53]. Studies show that the median age of the patients was 53.4 years (range 22-86) with a higher 
Table 2 Characteristics of patients with mucormycosis and COVID-19 reported in the literature

\begin{tabular}{|c|c|c|c|c|c|}
\hline Country (case) & Mean age & Sex & Underlying conditions & Type of Mucormycosis & Outcome \\
\hline India $(n=110)$ & 53.5 & $M: 86, F: 24$ & $\begin{array}{l}\text { DM:88,DKA:9 } \\
\text { CKD:9, RT:2 SOT:1,CGD:1 DCLD:1,TB:1 }\end{array}$ & $\begin{array}{l}\text { Rhino-Facial: Majority } \\
\text { Pulmonary: } 2.7 \%\end{array}$ & $\begin{array}{l}\text { Died:27,Alive:74 } \\
\text { LFU:4, Unchanged:4 } \\
\text { LAMA:5 }\end{array}$ \\
\hline $\operatorname{Iran}(n=20)$ & 51.6 & $M: 11, F: 9$ & DM:15,HM:2 & Rhino-Facial & Died:8, Alive:12 \\
\hline Turkey $(n=12)$ & 64.5 & M:9,F:3 & DM:9 & ROM, ROCM & Died:8,Alive:4 \\
\hline Egypt $(n=11)$ & 53 & $\mathrm{M}: 7, \mathrm{~F}: 4$ & $\mathrm{DM}: 7$ & $\mathrm{ROCM}$ & Died:5,Alive:6 \\
\hline USA $(n=10)$ & 51.4 & $M: 8, F: 2$ & $\mathrm{DM}: 7$ & $\begin{array}{l}\text { ROCM:3,ROM:3 } \\
\text { Pulmonary:4 }\end{array}$ & Died:8, Alive:2 \\
\hline The Netherlands $(n=4)$ & 60 & M:4 & DM:2, CLL:1 & ROCM, Pulmonary Disseminated & Died:3, Alive:1 \\
\hline UK $(n=2)$ & 22 & $M: 2$ & $\begin{array}{l}\text { Hypothyroidism: } 1 \\
\text { Obesity:1 }\end{array}$ & Disseminated & Died:2 \\
\hline Spain $(n=2)$ & 55 & $M: 2$ & $\mathrm{DM}: 1, \mathrm{RT}: 2$ & Rhino-Facial, Musculoskeletal & Alive:2 \\
\hline Australia $(n=1)$ & 53 & M:1 & MDS, AML & Pulmonary & Died \\
\hline Brazil $(n=1)$ & 86 & $M: 1$ & HTN & GIM & Died \\
\hline France $(n=1)$ & 55 & $M: 1$ & $\mathrm{FL}, \mathrm{HCT}$ & Pulmonary & Died \\
\hline Mexico $(n=1)$ & 24 & $F: 1$ & DKA & ROM & Died \\
\hline Italy $(n=1)$ & 66 & $M: 1$ & HTN & Pulmonary & Died \\
\hline $\operatorname{Iraq}(n=1)$ & 53 & $M: 1$ & DM & ROCM & Died \\
\hline
\end{tabular}

F female; $M$ male; DM diabetes mellitus; HTN hypertension; CKD chronic kidney disease; SOT solid organ transplant; DCLD Decompensated chronic liver disease; AML Acute myeloid leukemia; MDS Myelodysplastic syndrome; DKA Diabetic ketoacidosis; RT Renal transplant; FL Follicular lymphoma; HCT Hematopoietic cell transplantation; TB Tuberculosis; ROM rhino-orbital mucormycosis; ROCM rhino-orbito-cerebral mucormycosis; GIM gastrointestinal mucormycosis

prevalence of mucormycosis in men (75.7\%). The association of mucormycosis with uncontrollable diabetes has been proven [54]. Diabetes mellitus was the most common predisposing factor $(73.4 \%)$ for mucormycosis in COVID-19 patients [14, 15, 27, 32, 35, 44]. In 5 cases (2.8\%), no risk factors for mucormycosis were reported $[14,21,29,37]$. In our reported case, corticosteroidrelated hyperglycemia was observed in a patient with no history of diabetes. Predisposing factors for mucormycosis include diabetes mellitus, neutropenia, corticosteroid use, and immunodeficiency, among which diabetes is the most common risk factor linked with mucormycosis [55]. The severity of COVID-19 infection and its dangerous consequences are higher in individuals with diabetes. Glucocorticoids reduce mortality in patients with COVID-19 by reducing cytokine storm. Nevertheless, corticosteroids can increase the risk of fungal and bacterial secondary infections [56]. Therefore, use of steroids should be avoided in mild to moderate COVID-19 cases as they lead to dangerous results. Reports indicate that $82 \%$ of patients received corticosteroids.

The mean duration from between diagnosis of COVID-19 and the onset of symptoms of mucormycosis was 15 days $[15,18]$. Studies show that the most common clinical manifestation of mucormycosis is rhino-facial, followed by pulmonary and disseminated form. Herein, we report a case of mucormycosis in a 59-year-old male non-diabetic with COVID-19. The patient developed rhino-facial mucormycosis after the initiation of corticosteroid. The mean duration between diagnosis of COVID-19 infection and the onset of symptoms of mucormycosis was 15 days [13, $15,57]$. The present case indicates that in the presence of COVID-19, even short-term treatment with corticosteroids may be a predisposing factor in leading the patient to rhino-orbital mucormycosis. Studies show that glucose control, timely treatment with liposomal amphotericin $B$, and surgical debridement are effective in the management of mucormycosis. The prognosis of the disease depends on factors such as early diagnosis and management to limit the spread of infection into the intracranial space $[5,58]$. This study, in line with the results of other studies, reveals that the possible occurrence of secondary invasive fungal infections in patients with COVID-19 infection should not be neglected. Effort to maintain blood sugar and the rational use of corticosteroids in COVID-19 patients is recommended to reduce the risk of mucormycosis.

\section{Abbreviations \\ COVID-19: Coronavirus disease 2019; ARDS: Acute respiratory distress syn- drome; H\&E: Hematoxylin and eosin; PDA: Potato dextrose agar; CLSI: Clinical and Laboratory Standards Institute; MIC: Minimum inhibitory concentration; $R$. oryzae: Rhizopus oryzae; ML: Maximum-likelihood.}

\section{Acknowledgements}

The authors would like to thank the medical staff of the Razi Hospital in Qazvin, Iran. 


\section{Authors' contributions}

FM responsible for designing the manuscript and mycological analysis. MB and $\mathrm{NH}$ collaboration in mycological experiments. SS general ENT surgeon. All authors contributed to writing of the final version of the paper.

\section{Funding}

This study was financially supported by the Research Deputy of Qazvin University of Medical Sciences and the ethics approval code of this research is IR.QUMS.REC.1399.357.

\section{Availability of data and materials}

All data analyzed during this study are included in this published article.

\section{Declarations}

\section{Ethics approval and consent to participate}

The ethical approval was required and provided for this study, as stated by our institutional review board.

\section{Consent for publication}

The consent form has been signed by the family members of the patient.

\section{Competing interests}

The authors declared no potential conflicts of interest with respect to the research, authorship and/or publication of this article.

\section{Author details}

${ }^{1}$ Department of Medical Parasitology and Mycology, School of Medicine, Qazvin University of Medical Sciences, Shahid Bahonar Blvd, PO Box: 34199-15315, Qazvin, Iran. ${ }^{2}$ Medical Microbiology Research Center, Qazvin University of Medical Sciences, Qazvin, Iran. ${ }^{3}$ Department of Otolaryngologist, Fellowship of Rhinology, Razi Hospital, Qazvin, Iran. ${ }^{4}$ Department of Cellular and Molecular Research Center, Qazvin University of Medical Sciences, Qazvin, Iran. ${ }^{5}$ Metabolic Diseases Research Center, Research Institute for Prevention of Non-Communicable Diseases, Qazvin University of Medical Sciences, Qazvin, Iran.

Received: 9 March 2021 Accepted: 27 August 2021

Published online: 03 September 2021

\section{References}

1. Gibson PG, Qin L, Puah S. COVID-19 acute respiratory distress syndrome (ARDS): clinical features and differences from typical pre-COVID-19 ARDS. Med J Aust. 2020:213(2):54-6.

2. Szarpak L, Wisco J, Boyer R. How healthcare must respond to ventilatorassociated pneumonia (VAP) in invasively mechanically ventilated COVID19 patients. Am J Emerg Med. 2021. https://doi.org/10.1016/j.ajem.2021. 01.074.

3. Helleberg M, Steensen M, Arendrup MC. Invasive aspergillosis in patients with severe COVID-19 pneumonia. Clin Microbiol Infect. 2021;27(1):147-8

4. Gamaletsou MN, Sipsas NV, Roilides E, Walsh TJ. Rhino-orbital-cerebral mucormycosis. Curr Infect Dis Rep. 2012;14(4):423-34.

5. Cornely OA, Alastruey-Izquierdo A, Arenz D, Chen SC, Dannaoui E, Hochhegger B, Hoenigl M, Jensen HE, Lagrou K, Lewis RE. Global guideline for the diagnosis and management of mucormycosis: an initiative of the European Confederation of Medical Mycology in cooperation with the Mycoses Study Group Education and Research Consortium. Lancet Infect Dis. 2019;19(12):e405-21.

6. Mohammadi F, Hashemi SJ, Seyedmousavi SM, Akbarzade D. Isolation and characterization of clinical triazole resistance Aspergillus fumigatus in Iran. Iran J Public Health. 2018;47(7):994.

7. Petrikkos G, Skiada A, Lortholary O, Roilides E, Walsh TJ, Kontoyiannis DP. Epidemiology and clinical manifestations of mucormycosis. Clin Infect Dis. 2012;54:S23-34.

8. Talmi YP, Goldschmied-Reouven A, Bakon M, Barshack I, Wolf M, Horowitz Z, Berkowicz M, Keller N, Kronenberg J. Rhino-orbital and rhino-orbitocerebral mucormycosis. Otolaryngol Head Neck Surg. 2002;127(1):22-31.
9. Ferguson BJ. Mucormycosis of the nose and paranasal sinuses. Otolaryngol Clin N Am. 2000;33(2):349-65.

10. Challa S. Mucormycosis: Pathogenesis and pathology. Current Fungal Infection Reports. 2019;13(1):11-20.

11. Skiada A, Pavleas I, Drogari-Apiranthitou M. Epidemiology and diagnosis of mucormycosis: an update. J Fungi. 2020;6(4):265.

12. Mehta S, Pandey A. Rhino-orbital mucormycosis associated with COVID19. Cureus. 2020;12(9):1.

13. Garg D, Muthu V, Sehgal IS, Ramachandran R, Kaur H, Bhalla A, Puri GD, Chakrabarti A, Agarwal R. Coronavirus disease (Covid-19) associated mucormycosis (CAM): case report and systematic review of literature. Mycopathologia. 2021;19:1-10.

14. Moorthy A, Gaikwad R, Krishna S, Hegde R, Tripathi K, Kale PG, Rao PS, Haldipur D, Bonanthaya K. SARS-CoV-2, uncontrolled diabetes and corticosteroids - an unholy trinity in invasive fungal infections of the maxillofacial region? A retrospective, multi-centric analysis. J Maxillofac Oral Surg. 2021;73:1-8.

15. Sen M, Lahane S, Lahane TP, Parekh R, Honavar SG. Mucor in a viral land: a tale of two pathogens. Indian J Ophthalmol. 2021;69(2):244.

16. Sarkar S, Gokhale T, Choudhury SS, Deb AK. COVID-19 and orbital mucormycosis. Indian J Ophthalmol. 2021;69(4):1002.

17. Sharma S, Grover M, Bhargava S, Samdani S, Kataria T. Post coronavirus disease mucormycosis: a deadly addition to the pandemic spectrum. J Laryngol Otol. 2021;135(5):442-7.

18. Revannavar SM, Supriya P, Samaga L, Vineeth V. COVID-19 triggering mucormycosis in a susceptible patient: a new phenomenon in the developing world? BMJ Case Rep. 2021;14(4):e241663.

19. Mishra N, Mutya $V$, Thomas A. A case series of invasive mucormycosis in patients with COVID-19 infection. Int J Otorhinolaryngol Head Neck Surg. 2021;7(5):867-70

20. Saldanha M, Reddy $R$, Vincent MJ: of the article: paranasal mucormycosis in COVID-19 patient. Indian Journal of Otolaryngology and Head \& Neck Surgery 2021:1-4.

21. Maini A, Tomar G, Khanna D, Kini Y, Mehta H, Bhagyasree V. Sino-orbital mucormycosis in a COVID-19 patient: a case report. Int J Surg Case Rep. 2021:82:105957.

22. Nehara HR, Puri I, Singhal V, Sunil I, Bishnoi BR, Sirohi P. Rhinocerebral mucormycosis in COVID-19 patient with diabetes a deadly trio: case series from the north-western part of India. Indian J Med Microbiol. 2021:39(3):380-3.

23. Rao R, Shetty AP, Nagesh CP. Orbital infarction syndrome secondary to rhino-orbital mucormycosis in a case of COVID-19: clinico-radiological features. Indian J Ophthalmol. 2021;69(6):1627-30.

24. Meshram HS, Kute VB, Chauhan S, Desai S. Mucormycosis in postCOVID-19 renal transplant patients: a lethal complication in follow-up. Transpl Infect Dis. 2021;2021:e13663.

25. Shah D, Talwar D, Kumar S, Acharya S, Dubey A: Mucormycosis as a complication of LONG COVID: A case series. 2021

26. Karimi-Galougahi M, Arastou S, Haseli S. Fulminant mucormycosis complicating coronavirus disease 2019 (COVID-19). Int Forum Allergy Rhinol. 2021;1:1029-30.

27. Ahmadikia K, Hashemi SJ, Khodavaisy S, Getso Ml, Alijani N, Badali H, Mirhendi H, Salehi M, Tabari A, Mohammadi Ardehali M:The double-edged sword of systemic corticosteroid therapy in viral pneumonia: A case report and comparative review of influenza-associated mucormycosis versus COVID-19 associated mucormycosis. Mycoses 2021.

28. Tabarsi P, Khalili N, Pourabdollah M, Sharifynia S, Naeini A, Ghorbani J, Mohamadnia A, Abtahian Z, Askari E: COVID-19 associated rhinosinusitis mucormycosis due to Rhizopus arrhizus: A rare but potentially fatal infection occurring after treatment with corticosteroids. 2021.

29. Veisi A, Bagheri A, Eshaghi M, Rikhtehgar MH, Rezaei Kanavi M, Farjad R: Rhino-orbital mucormycosis during steroid therapy in COVID-19 patients: a case report. Eur J Ophthalmol 2021

30. Pakdel F, Ahmadikia K, Salehi M, Tabari A, Jafari R, Mehrparvar G, Rezaie Y, Rajaeih S, Alijani N, Barac A: Mucormycosis in patients with COVID-19: a cross-sectional descriptive multicenter study from Iran. Mycoses 2021

31. Sargin FAM, Karaduman S, Sungurtekin H. Severe rhinocerebral mucormycosis case developed after COVID 19. J Bacteriol Parasitol. 2021;12:386.

32. Bayram N, Ozsaygılı C, Sav H, Tekin Y, Gundogan M, Pangal E, Cicek A, Özcan I. Susceptibility of severe COVID-19 patients to rhino-orbital 
mucormycosis fungal infection in different clinical manifestations. Jpn J Ophthalmol. 2021;1:1-11.

33. Ashour MM, Abdelaziz TT, Ashour DM, Askoura A, Saleh MI, Mahmoud MS. Imaging spectrum of acute invasive fungal rhino-orbital-cerebral sinusitis in COVID-19 patients: a case series and a review of literature. Neuroradiol. 2021. https://doi.org/10.1016/j.neurad.2021.05.007.

34. Fouad YA, Abdelaziz TT, Askoura A, Saleh MI, Mahmoud MS, Ashour DM, Ashour MM. Spike in rhino-orbital-cerebral mucormycosis cases presenting to a tertiary care center during the COVID-19 pandemic. Front Medicine. 2021;8:1.

35. Dallalzadeh LO, Ozzello DJ, Liu CY, Kikkawa DO, Korn BS. Secondary infection with rhino-orbital cerebral mucormycosis associated with COVID-19. Orbit. 2021;1:1-4.

36. Werthman-Ehrenreich A. Mucormycosis with orbital compartment syndrome in a patient with COVID-19. Am J Emerg Med. 2021:42(264):e265-e264.

37. Placik DA, Taylor WL, Wnuk NM. Bronchopleural fistula development in the setting of novel therapies for acute respiratory distress syndrome in SARS-CoV-2 pneumonia. Radiol Case Rep. 2020;15(11):2378-81.

38. Mekonnen ZK, Ashraf DC, Jankowski T, Grob SR, Vagefi MR, Kersten RC, Simko JP, Winn BJ. Acute invasive rhino-orbital mucormycosis in a patient with COVID-19-associated acute respiratory distress syndrome. Ophthal Plast Reconstr Surg. 2021;37(2):e40.

39. Alekseyev K, Didenko L, Chaudhry B. Rhinocerebral mucormycosis and COVID-19 pneumonia. J Med Cases. 2021;12(3):85.

40. Johnson AK, Ghazarian Z, Cendrowski KD, Persichino JG. Pulmonary aspergillosis and mucormycosis in a patient with COVID-19. Med Mycol. 2021;32:64-7.

41. Kanwar A, Jordan A, Olewiler S, Wehberg K, Cortes M, Jackson BR. A fatal case of Rhizopus azygosporus pneumonia following COVID-19. J Fungi. 2021;7(3):174

42. Khatri A, Chang K-M, Berlinrut I, Wallach F. Mucormycosis after Coronavirus disease 2019 infection in a heart transplant recipient-case report and review of literature. J Med Mycol. 2021;187:101125.

43. Khan N, Gutierrez CG, Martinez DV, Proud KC. A case report of COVID-19 associated pulmonary mucormycosis. Arch Clin Cases. 2020;7(3):2027.

44. Buil JB, van Zanten AR, Bentvelsen RG, Rijpstra TA, Goorhuis B, van der Voort S, Wammes LJ, Janson JA, Melchers M, Heusinkveld M. Case series of four secondary mucormycosis infections in COVID-19 patients, the Netherlands, December 2020 to May 2021. Eurosurveillance. 2021;26(23):2100510.

45. Krishna V, Morjaria J, Jalandari R, Omar F, Kaul S. Autoptic identification of disseminated mucormycosis in a young male presenting with cerebrovascular event, multi-organ dysfunction and COVID-19 infection. IDCases. 2021;23:e01172

46. Hanley B, Naresh KN, Roufosse C, Nicholson AG, Weir J, Cooke GS, Thursz M, Manousou P, Corbett R, Goldin R. Histopathological findings and viral tropism in UK patients with severe fatal COVID-19: a post-mortem study. Lancet Microbe. 2020;1 (6):e245-53.

47. Arana C, Cuevas Ramírez RE, Xipell M, Casals J, Moreno A, Herrera S, Bodro M, Cofan F, Diekmann F, Esforzado N. Mucormycosis associated with covid19 in two kidney transplant patients. Transpl Infect Dis. 2021;89:e13652.

48. do Monte Junior ES. Rare and fatal gastrointestinal mucormycosis (zygomycosis) in a COVID-19 patient: a case report. Clin Endosc. 2020;53(6):746.

49. Zurl C, Hoenigl M, Schulz E, Hatzl S, Gorkiewicz G, Krause R, Eller P, Prattes J. Autopsy proven pulmonary mucormycosis due to Rhizopus microsporus in a critically ill COVID-19 patient with underlying hematological malignancy. J Fungi. 2021;7(2):88.

50. Bellanger A-P, Navellou J-C, Lepiller Q, Brion A, Brunel A-S, Millon L, Berceanu A: Mixed mold infection with Aspergillus fumigatus and Rhizopus microsporus in a severe acute respiratory syndrome Coronavirus 2 (SARSCoV-2) patient. Infectious Diseases Now 2021.

51. Waizel-Haiat S, Guerrero-Paz JA, Sanchez-Hurtado L, Calleja-Alarcon S, Romero-Gutierrez L. A case of fatal rhino-orbital mucormycosis associated with new onset diabetic ketoacidosis and COVID-19. Cureus. 2021;13(2):1.

52. Pasero D, Sanna S, Liperi C, Piredda D, Branca GP, Casadio L, Simeo R, Buselli A, Rizzo D, Bussu F. A challenging complication following SARS-CoV-2 infection: a case of pulmonary mucormycosis. Infection. 2020;16:1-6.

53. Farid HA, Hashim AR, Hasrat NH. Rhinocerebral mucormycosis as a COVID-19-related complication: a case report from Basra City, Southern Iraq. J Glob Sci Res. 2021;6(5):1369-74.

54. Rammaert B, Lanternier F, Poirée S, Kania R, Lortholary O. Diabetes and mucormycosis: a complex interplay. Diab Metab. 2012;38(3):193-204.

55. Reid G, Lynch III JP, Fishbein MC, Clark NM: Mucormycosis. In: Seminars in respiratory and critical care medicine: 2020: Thieme Medical Publishers; 2020: 099114

56. Rawson TM, Wilson RC, Holmes A. Understanding the role of bacterial and fungal infection in COVID-19. Clin Microbiol Infect. 2021;27(1):9.

57. Paul SS, Kumar R, Meena VP, Ramprasad A, Garg P, Keri VC, Singh K, Dhir A, Sakhtivel P, Vig S: Clinical characteristics and outcomes of 16 cases with COVID19 and mucormycosis: experience from a tertiary care center in India and review of literature. 2021.

58. Patel A, Kaur H, Xess I, Michael J, Savio J, Rudramurthy S, Singh R, Shastri P, Umabala P, Sardana R. A multicentre observational study on the epidemiology, risk factors, management and outcomes of mucormycosis in India. Clin Microbiol Infect. 2020;26(7):944.

\section{Publisher's Note}

Springer Nature remains neutral with regard to jurisdictional claims in published maps and institutional affiliations.
Ready to submit your research? Choose BMC and benefit from:

- fast, convenient online submission

- thorough peer review by experienced researchers in your field

- rapid publication on acceptance

- support for research data, including large and complex data types

- gold Open Access which fosters wider collaboration and increased citations

- maximum visibility for your research: over $100 \mathrm{M}$ website views per year

At BMC, research is always in progress.

Learn more biomedcentral.com/submissions 